Área: Ciencias de la Salud

Salud, Naturales, Sociales y Formales

Disciplina: Medicina

Tipo de artículo: Reporte de caso

\title{
Neumonía por Mycoplasma, a propósito de un caso
}

\section{Autores}

Cruz Barrera Aura a, b, Romero Soriano Katherine a,

Fecha de envío: 16/03/2019

Fecha de aprobación: 15/11/2019

Afiliación institucional

a. Universidad Católica de Santiago de Guayaquil

b. Hospital Roberto Gilbert Elizalde, Guayaquil.

\section{Correspondencia}

Romero Soriano Katherine, Posgrado de Pediatría. kars8000@live.com

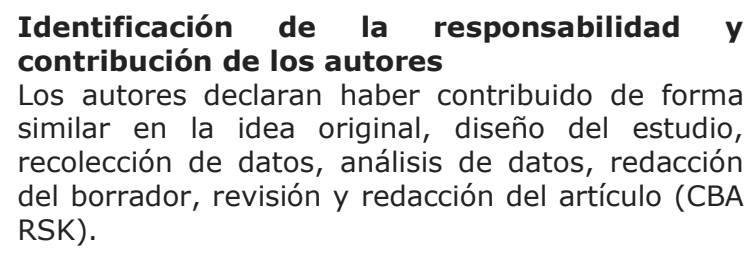

\section{Fuente de financiamiento}

Autofinanciado.

\section{Conflicto de interés}

Los autores declaran no tener conflictos de interés con la publicación de este artículo.

\section{Citación sugerida}

Cruz Barrera A, Romero Soriano K. Neumonía por micoplasma, a propósito de un caso. Rev Cien Ec. [Internet]. 2019; 1(6): 5-9. doi: $10.23936 /$ rce.v1i6.8

\section{Resumen}

La neumonía adquirida en la comunidad (NAC) es la primera causa de mortalidad infantil en los países en vías de desarrollo. La neumonía por Mycoplasma pneumoniae es una infección normalmente autolimitada, que afecta mayormente a los niños de edad escolar y adultos jóvenes, la aparición de complicaciones o secuelas es más común a menor edad. A continuación, se presenta el caso de una niña de 10 años con el diagnóstico de Neumonía complicada por Mycoplasma pneumoniae.

Palabras clave: Mycoplasma pneumoniae; neumonía por Mycoplasma; informes de casos; 


\title{
ECV Ciencia Ecuador \\ Revista científica multidisciplinar sobre Ciencias de la Salud, Naturales, Sociales y Formales
}

\author{
Mycoplasma pneumonia, about a case
}

\begin{abstract}
Community-acquired pneumonia (CAP) is the leading cause of infant mortality in developing countries. Mycoplasma pneumoniae pneumonia is a normally self-limited infection that mostly affects school-age children and young adults, the occurrence of complications or sequelae is more common at a younger age. The case of a 10-yearold girl with the diagnosis of Pneumonia complicated by Mycoplasma pneumoniae is presented below.
\end{abstract}

Keywords: Mycoplasma pneumoniae; pneumonia, mycoplasma; case reports;

\section{Introducción}

En los últimos años, las infecciones de las vías respiratorias han superado a la enfermedad diarreica como principal causa de morbimortalidad infantil en países en desarrollo, a tal punto que la neumonía es la principal causa de muerte en niños menores de 5 años. ${ }^{1}$

Frente a esta situación se hace necesario en pacientes que presentan neumonía determinar el agente etiológico para iniciar tratamiento adecuado y oportuno. Sin embargo, en algunos casos se hace imposible dicha determinación por falta de métodos rápidos de diagnóstico y es ahí cuando se instaura tratamiento empírico ante una sospecha clínica. Esta se debe sustentar en la presunción de determinados microorganismos en base a la identificación de características epidemiológicas, clínicas, radiológicas o de laboratorio usualmente asociada con ellos. 2

Entre los patógenos respiratorios, el Mycoplasma pneumoniae es uno al que frecuentemente se le asigna un patrón clínico-radiológico y epidemiológico muy específico. Entre estas se incluyen prevalencia relativamente baja, predominio en escolares y adolescentes, patrón radiológico de tipo predominantemente intersticial. Sin embargo, la ausencia de estas

\section{Abstrato}

A pneumonia adquirida na comunidade (PAC) é a principal causa de mortalidade infantil nos países em desenvolvimento. A pneumonia por Mycoplasma pneumoniae é uma infecção normalmente autolimitada que afeta principalmente crianças em idade escolar e adultos jovens, a ocorrência de complicações ou sequelas é mais comum em uma idade mais jovem. O caso de uma menina de 10 anos com diagnóstico de Pneumonia complicada por Mycoplasma pneumoniae é apresentado abaixo.

Palavras-chave: Mycoplasma pneumoniae; pneumonia por mycoplasma; relatos de casos;

características no debe descartar la sospecha diagnóstica. 2

El objetivo de este artículo es presentar un caso con neumonía por Mycoplasma confirmada, con presentación atípica.

\section{Caso clínico}

Se trata de un paciente femenino de 10 años 10 meses de edad, con antecedente de síndrome de Down sin cardiopatía estructural, que se hospitaliza por cuadro clínico de 8 días caracterizado por tos seca no rubicundizante, no cianozante, la cual se torna ocasionalmente emetizante acompañado de rinorrea hialina. Además, 48 horas previas a su ingreso se agrega alza térmica no cuantificada, hiporexia y dolor abdominal difuso de moderada intensidad, razón por la cual inicialmente acude a facultativo externo, quien prescribe terapia antimicrobiana múltiple (no especificada al interrogatorio) sin evidenciar mejoría clínica, por lo que su madre decide acudir a institución.

A su admisión, se presenta febril $\left(38^{\circ} \mathrm{C}\right)$, con piel pálida y mucosas secas, taquicárdica (130 latidos por minuto), con Ilenado capilar de 3 segundos; al examen físico resalta polipnea (FR 35 por minuto, percentil 90 para su edad) a pesar de no evidenciar esfuerzo respiratorio, se constató desaturación en rango 81 a $90 \%$, acompañado a la percusión en ambos tercios inferiores del tórax con 


\section{Salud, Naturales, Sociales y Formales}

vibraciones vocales y murmullo vesicular disminuido, a la auscultación estertores crepitantes bilaterales, sin datos de obstrucción bronquial. Los estudios complementarios a su ingreso destacan: hemograma con 8077 glóbulos blancos, $77 \%$ de neutrófilos y PCR elevada. Radiografía de tórax con imágenes de infiltrado alveolar en ambas bases pulmonares (imagen 1, 1).

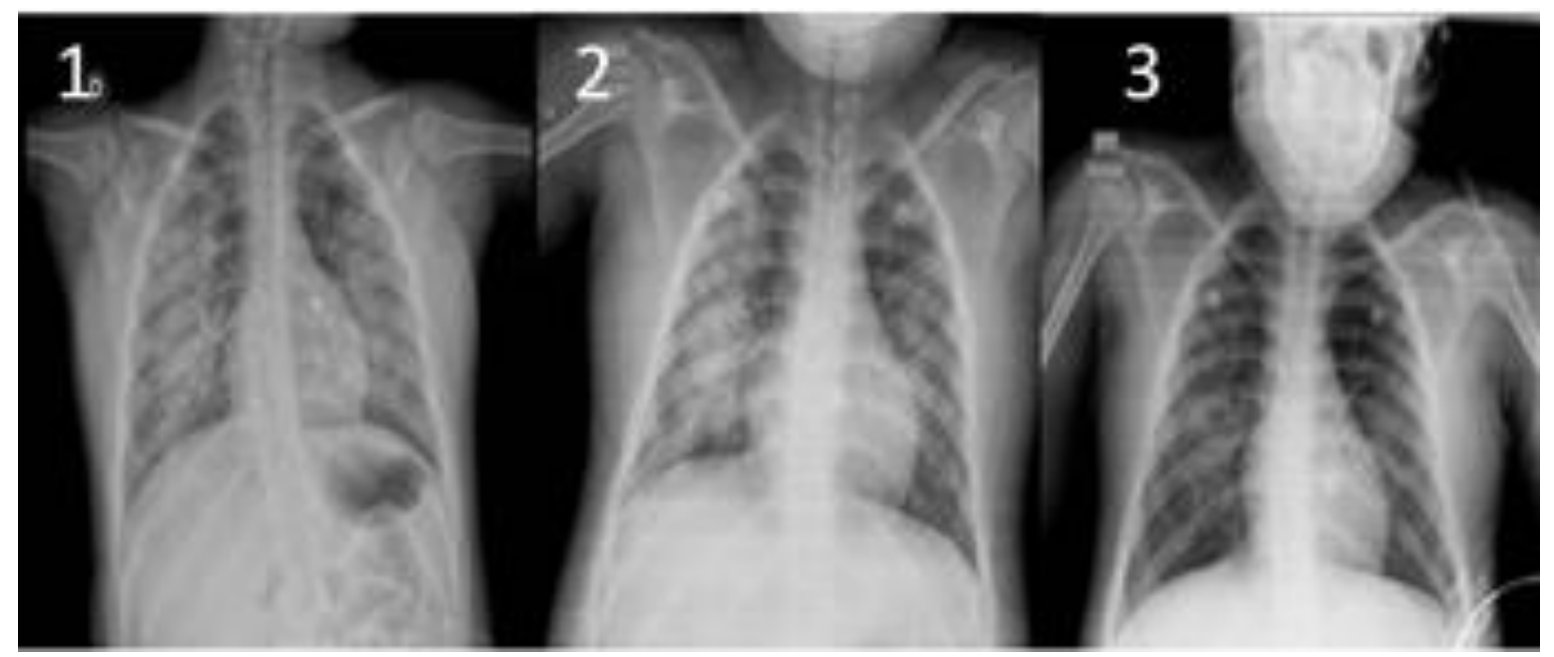

Imagen 1. Imágenes radiológicas del paciente. 1 se observan infiltrados alveolares perihiliares bilaterales. 2 se observan infiltrado intersticio alveolares perihiliares bilaterales, senos costodiafragmáticos libres. 3 infiltrado intersticial a predominio de hemitórax derecho, reforzamiento hiliar bilateral, ángulos costofrénicos libres.

Se aborda como infección aguda de las vías respiratorias inferiores (neumonía de la comunidad) y se decide colocar inicialmente soporte de oxígeno por cánula nasal a 3 litros, con lo que no mejora su patrón respiratorio, se realiza control gasométrico que reporta $\mathrm{PH} 7.46, \mathrm{pCO} 2$ 31.7, $\mathrm{PO} 2$ 180.5, HCO3 22.5, BE -0.5, Sat. 99,5\%, lactato 1.2 $\mathrm{mmol} / \mathrm{l}$, con lo que se decide colocar dispositivo de oxígeno por alto flujo a FiO2 70 $\%$ a 10 L. con el que pasa a cuidados intermedios pediátricos. Adicionalmente impresiona algún grado de deshidratación, por lo que se canaliza vía periférica para manejo de líquidos de mantenimiento a flujo basal con solución isotónica con el que mejora su estado de hidratación y mantiene gastos urinarios adecuados.

Se inició tratamiento antibiótico para gérmenes más frecuentes por grupo etario con amoxicilina más ácido clavulánico, previa toma de hemocultivos por dos. Sin embargo, ante clínica desfavorable durante las primeras horas de hospitalización, además de su grupo etario, patrón radiológico y antecedentes epidemiológicos (familiares con cuadros respiratorios de evolución subaguda) se sospecha de neumonía por gérmenes atípicos y solicita serología de Mycoplasma pneumoniae y además se decide ampliar cobertura antibiótica a cefalosporina de $3^{a}$ generación más claritromicina para cubrir gérmenes atípicos. En su cuarto día de hospitalización la serología de Mycoplasma se reportó positiva, confirmando el diagnóstico. Sin embargo, debido a controles de

Rev Cien Ec 2019; 1(6)

doi: $10.23936 /$ rce.v1i6.8 radiográficos de tórax seriados (figura 1, 2 y 3 ) en iguales condiciones se consideró realizar estudios de BDK en aspirado gástrico como parte de su abordaje, los cuales resultaron negativos. Los hemocultivos resultaron negativos por dos.

Durante su estancia en unidad de cuidados intermedios pediátricos su evolución fue favorable pudiéndose destetar del soporte de alto flujo a las 72 horas, posteriormente es llevada a sala de pediatría con soporte de oxígeno de bajo flujo pudiéndose destetar del mismo después de 48 horas, posterior a lo cual fue externada con indicación de completar esquema de antibiótico vía oral, control de signos de alarma y cita por consulta externa de pediatría en 48 horas.

\section{Discusión}

Las infecciones respiratorias son una causa importante de morbimortalidad en población pediátrica, se estima que en el mundo mueren alrededor de 2 millones de niños al año por esta causa. Si bien los virus son la etiología más frecuente de NAC en niños, algunas bacterias también adquieren especial consideración en su etiología, dentro de los cuales existen aquellos agentes que producen un curso clínico o radiológico poco habitual, diferente al de las bacterias "tradicionales". 2

El término "neumonías atípicas" fue descrito por primera vez en 1944 con la existencia de un microorganismo (anteriormente denominado como "agente Eaton") que era capaz de producir cuadros de neumonías atípicas en humanos. Casi dos décadas 


\section{Salud, Naturales, Sociales y Formales}

después se determinó que este correspondía a una bacteria de la familia de los Mycoplasmas, siendo denominado posteriormente como Mycoplasma pneumoniae. Otros agentes causales de neumonía atípica son: Chlamydophila pneumoniae, Coxiella burnetti, Legionela pneumophila y Chlamydophila psitacci. 1, 2

Con respecto al Mycoplasma pneumoniae, la infección afecta tanto a niños como adultos en forma endémica sin grandes variaciones estacionales, sin embargo, la proporción de casos aumenta significativamente durante el verano en países con clima templado, debido a una menor incidencia de otros patógenos respiratorios y este ha sido denominado periodo ventana; así, en Estados Unidos y Europa, se le considera responsable de hasta el $40 \%$ de las NAC en niños, con un requerimiento de internación hospitalaria que oscila del 2-18 \% de los ingresos hospitalarios, cifras parecen ser similares que tienden a ser parecidas en otras regiones del mundo (en Japón el $44 \%$ y $34 \%$ en África). ${ }^{1,2-5}$

El síntoma más frecuente es la tos no productiva; inicialmente sin fiebre, la cual puede aparecer posteriormente, se acompaña de cefalea, coriza, otitis media y malestar general; en las radiografías se puede observar opacidades uni o bilaterales, y en 10 $\%$ de los casos puede aparecer derrame pleural; el diagnóstico se realiza con la detección del microorganismo mediante cultivos o PCR, o por la detección de anticuerpos IgG e IgM. ${ }^{3}$

La enfermedad tiende ser benigna y autolimitada en la mayoría de los casos, los cuales pueden ser manejados de forma ambulatoria ${ }^{8}$; a pesar de esto, en algunas ocasiones puede producir una neumonía fulminante con compromiso pulmonar severo. Se han descrito casos de neumatocele, absceso pulmonar, bronquiectasias, fibrosis intersticial crónica y síndrome de distrés respiratorio. 2,5

Se ha descrito que hasta en $37 \%$ de casos podrá observarse alteraciones en tomografía computada entre los 1 y 2,2 años, tales como, atrapamiento aéreo y bronquiectasias; también se ha mencionado la aparición de alteraciones en la capacidad de difusión pulmonar 6 meses después de una NAC por M. pneumoniae; no se recabaron datos con respecto a la mortalidad en niños con NAC por M. pneumoniae, sin embargo, se ha reportado muertes en pacientes con encefalitis secundaria. En niños, el riesgo de presentar una enfermedad severa aumenta en casos de infecciones concomitantes, inmunosupresión, anemia de células falciformes, síndrome de Down y disfunción cardiopulmonar. ${ }^{1}$

En cuanto al tratamiento, este disminuye el riesgo de alteraciones posteriores de la capacidad de difusión pulmonar, mas no el riesgo de contagio a otras personas, ya que se ha documentado persistencia de transmisión a contactos familiares de pacientes con infección por M. pneumoniae, a pesar de haber recibido un tratamiento antibiótico adecuado. Con respecto a la antibioticoterapia, dado que se trata de una bacteria que no posee pared celular, no responde a tratamiento con ß-lactámicos, siendo a aquellos que interfieren con la síntesis de proteínas o ADN, como tetraciclinas, macrólidos y quinolonas. ${ }^{1}$

\section{Conclusión}

En conclusión, la infección por $M$. pneumoniae produce manifestaciones inespecíficas y variables de un caso a otro, a veces difíciles de distinguir de otras infecciones respiratorias, incluso virales. En nuestro caso la sospecha clínica fue determinante en el inicio oportuno del tratamiento, ante el cual la paciente presentó evolución favorable. Se hace indispensable entonces, una historia clínica adecuada, para determinar el cuadro clínico que permitirá conocer los signos y síntomas más frecuentes de presentación, lo que lleva a un mayor índice de sospecha. Ello permitirá un inicio precoz del tratamiento antimicrobiano, acortando así la duración de la enfermedad y disminuyendo el riesgo de sus complicaciones.

\section{Referencias}

1. Paul M, García C, Vega Briceño L. Infección por Mycoplasma pneumoniae. Neumol Pediatr [Internet]. 2017 [cited 10 January 2019]; 140-146. Available from: neumologiapediatrica.cl.

2. Parra W. Neumonías atípicas. Neumol Pediatr [Internet]. 2017 [cited 10 January 2019]; 74-78. Available from: neumologiapediatrica.cl.

3. Gómez-Meléndez GA, DuránGuzmán JR, Berny-Chávez DA, Salcedo-Roldán MI. Neumonía por Mycoplasma pneumoniae: presentación de un caso y breve revisión bibliográfica. Med Int Mex [Internet]. 2012[cited 10 January 2019];28(1):81-88. Available from: medigraphic.

4. Palencia-Vizcarra RJ, Palencia-Díaz R. Neumonía atípica. Med Int Méx [Internet]. 2014[cited 10 January 2019];30:482-488. Available from: medigraphic. 
5. Úbeda Sansano MI, Murcia García J, Asensi Monzó MT. Neumonía adquirida en la comunidad. Protocolos del GVR- Asociación Española de Pediatría de Atención Primaria [Internet]. 2017 [cited 10 January 2019];30:482-488. Available from: aepap.org.

6. Lui G, IM, Lee N, Rainer T, Man S, Cockram C et al. Role of 'atypical pathogens' among adult hospitalized patients with community-acquired pneumonia. Respirology [Internet]. 2009 [cited 10 January 2019];14(8):1098-1105. DOI: 10.1111/j.1440-1843.2009.01637.x.

7. Smith L. Mycoplasma Pneumonia and Its Complications. Infectious Disease Clinics of North America [Internet]. 2010 [cited 10 January 2019];24(1):57-60. DOI: 10.1016/j.idc.2009.10.006.
8. Cunha C. The First Atypical Pneumonia: The history of the discovery of Mycoplasma pneumoniae. Infectious disease clinics of North America [Internet]. 2010 [cited 20 January 2019];24(1):1-5. DOI: 10.1016/j.idc.2009.10.007.

9. Xiong $\mathrm{YH}$, Deng R, Fu RR, Li DZ, Chen J, Chen YS, Hu CP, Li JS, Wang RQ, Wei LP, Zhong XN, Tian GZ, Mu L, Wan HY, Yu Q, He $P$, Ma JJ, Gao ZC. [Atypical pathogens in adult patients admitted with communityacquired pneumonia]. Zhonghua Jie $\mathrm{He} \mathrm{He}$ Hu Xi Za Zhi. 2010 Sep;33(9):646-50. Chinese. PMID: 21092629. 